Article

\title{
Views of Irish Farmers on Smart Farming Technologies: An Observational Study
}

\author{
Jithin Das V. ${ }^{1, t, \ddagger}$, Shubham Sharma ${ }^{2, *, \ddagger(\mathbb{D})}$ and Abhishek Kaushik ${ }^{3, *(\mathbb{D})}$ \\ 1 School of Computing, Dublin Business School, D02 WC04 Dublin, Ireland; 10360975@mydbs.ie or \\ jithindasv@gmail.com \\ 2 School of Food Science and Environmental Health, TU Dublin, D01 HV58 Dublin, Ireland \\ 3 ADAPT Centre, School of Computing, Dublin City University, D09 W6Y4 Dublin, Ireland \\ * Correspondence: shubham.sharma@dit.ie (S.S.); abhishek.kaushik2@mail.dcu.ie (A.K.) \\ + Current address: 13/14 Aungier St, D02 WC04 Dublin, Ireland. \\ $\ddagger$ These authors contributed equally to this work.
}

Received: 4 March 2019; Accepted: 9 April 2019; Published: 12 April 2019

check for updates

\begin{abstract}
The primary objective of this research is to find the disparity for slow adoption of Smart Farming Technologies (SFT) in Ireland. The usage of Cloud Computing technology among Irish farmers would help to find out the adoption behaviour barrier and way to enhance from the present system. The research will also help us to indicate the reasons for farmers in adopting and not adopting any technology. The research followed a mixed method where both surveys and interviews were used to collect the data from Irish farmers. A total sample of 32 farmers were selected through snowball sampling with the help of social websites. This study explored the major factors in adopting new technology among Irish farmers. It also helped to find the perception of farmers and ways to improve from the present system. The result shows that Cloud Computing adoption among the young farmers is greater while it is lower among the old farmers in Ireland.
\end{abstract}

Keywords: smart farming; smart farming technology; cloud computing; Irish farmers

\section{Introduction}

The green revolution mechanized agriculture and now agriculture is being digitalized like any other industry. The change from the traditional work-flow of managing farm to closely monitor the crop, animal and land precisely by identifying the temporal and spatial variability of land, animals and crop is called precision farming [1]. However, smart farming is an extension to precision farming. In precision agriculture, land is managed by location, while smart farming uses data and location of the field for better management and helps to carry out real-time events in the farm [1]. Outstanding development on the Internet of Things and Cloud Computing (CC) technology propelled Smart farming [2]. However, farming using Cloud technology is termed as "farms in the cloud". Teagasc “Technology Foresight Report 2035" suggested smart farming as farms in the cloud because a farm can be run in real time with the help of data and algorithm [3].

Farmers in the USA show great interest in using precision technologies. More than $80 \%$ of farmers use Global Navigation Satellite System (GNSS) technology in the USA [4]. Apart from the USA, other developed countries like Canada, Australia and European countries like Sweden, Denmark, Finland and Germany show good usage of precision technology [5]. However, uptake of technology in Europe is very low and it reaches only 35\% [6]. Irish agriculture is dominated by grass, 163,000 people are employed in this sector, accounting for 26-billion-euro turnover in a year [7]. According to the Department of Agriculture Food and the Marine (DAFM) food wise 2025 report, Ireland has great opportunities in the global market due to its reputation in sustainable agriculture 
and its potential in foreign direct investment but financial competitiveness and lack of skill are weaknesses faced in expanding the dairy, meat, poultry and fishery farm [7]. 4.4 million hectares of land in Ireland is used for agriculture and the average size of a farm in Ireland is 32.5 hectares [8]. More than $80 \%$ of the land is used for pasture and the rest for grazing and other farms. However, half of the farming population has part-time jobs and the average age of Irish farmers is 56 [8]. To sustain in the global market, Ireland needs to embrace technology for increasing productivity. According to Teagasc Technology Foresight 2035 report, the uptake of Irish farmers in new technology is low [3]. The data report from the European Agricultural Machinery Association (CEMA) also shows that Ireland uptake in precision technology is low compared to other countries like France, Germany, and Denmark etc. [9]. The primary objective of this research was to find the disparity for the slow adoption of Smart Farming Technologies (SFT) in Ireland. The usage of CC technology among Irish farmers would help to find out the adoption behaviour, barrier and way to enhance from the present system. The research will also help to find the drivers of farmers who adopted and who did not adopt any technology.

\subsection{Technologies Propelling Smart Farming}

Technology boosting smart farming can be broadly classified on the basis of hardware and software. GNSS is proposed by the US and made available to the world [9]. Integration with Real-time Kinematic(RTK) technology increase its accuracy and become widely available to all customers $[10,11]$. The adoption of GNSS on farms of the US is $70 \%$ while it is $10 \%$ in European countries $[12,13]$.

\subsubsection{Hardware Basis}

The development of Unmanned Aerial Vehicles (UAV) or Drones had a great scope in farming. It can be used in virtual fencing, herd management and can even check the state of crops [14]. According to the PWC (Price water house Coopers); one of the largest professional service firms, reported that the current global market for drone in agriculture stands at $\$ 32.4$ billion. Unmanned Vehicle Systems International Association states that the usage of drones in agriculture would increase to $80 \%$ across the globe. However, regulation plays a barrier in the adoption of drones, especially in Europe [12,15]. Another technology in digitalized agriculture is robotics. Cost is the main barrier for advanced technology like robotics and the reception is low all over the world. It is mainly used in the dairy industry for automated milking but 30\% of farms in Netherland and $2 \%$ of US farms use this technology [4]. According to the Teagasc Report, uptake of robotic milking in Ireland is also low due to the cost and complexity of equipment [3]. Radio Frequency Identification (RFID) is a tag system that is fixed manually on the ear of animals or even used in vegetables that helps to receive data about that object or animal remotely. However, this technology is used widely in robotic milking and feeding systems [11]. The increased amount of usages of RFID technology is observed in Central and Northern European countries like Germany, Denmark, and Sweden etc. compared to developed countries like Ireland, UK, and France etc. [16]. Internet of Things (IoT) is a hardware device that can send or receive data and could be connected to the internet or external network or application. An IoT device can be of any form, ranging from sensors to wearable watches [17].

\subsubsection{Software Basis}

Farm Management Information Systems (FMIS) are basically software tools used to collect farm data and process it for decision making and the results would be helpful for farmers. They are best used in field operation management, herd management, yield estimation, machinery maintenance, human resource management etc. However, most of the farms in Europe are small that make FMIS adoption slower [4]. The development in Big Data and Machine Learning transformed agriculture from mechanical usage to data savvy agriculture. Predicting the result without any external programming code from the data available is known as Machine Learning [15,18]. While Big Data cannot be specified 
as a technology; however, in agriculture, it is a collection of a large amount of data generated from different sources like IoT sensors, UAV, Global Positioning System (GPS) etc., that need to be processed and finally transform these data into useful information. However, the result obtained will be helpful for farmers in decision-making processes [19].

\subsection{Drivers for Adoption}

There are drivers for adoption of SFT like CC for the agriculture sector. Rising demand for food worldwide needs to expand the current technologies to increase the yield and efficiency. According to the report from the United Nations, the world population is growing by 1.10 percent each year, it would reach 8.6 billion in 2030 and 9.8 billion by 2050 [20]. The "Food-wise 2025" report suggests that the growing population needs an overall food production of $70 \%$ increase by 2050 [7]. Moreover, the report also added that the future need for food production can be fulfilled only by embracing and utilizing new technologies [7]. Introducing efficient SFT-like cloud technology techniques would help to optimize the yield.

The agricultural activities in the traditional method could lead to a rising in carbon emission to the atmosphere. The Climate Smart Agriculture (CSA) (2016) report suggests that forestry, agriculture and other land use contribute $24 \%$ of global greenhouse gas emission and it can reach $30 \%$ by 2025 [21]. The recent Teagasc report shows that increase in agriculture production of Ireland increased the carbon footage by $9 \%$ by 2030 [22]. The CSA report suggests to uptake new technologies to farmers to tackle the situation [20]. However, according to Symeonak et al., CC would aid CSA by helping to increase the yield and efficiency. It facilitates agricultural information storage, access, and management [23]. The CSA (2016) report suggests that Ireland has a great opportunity and potential to grow its production by $85 \%$ by the year 2025, that is a growth of 19 billion Euro. The demand for protein food has increased globally and it would enhance the export market of beef, seafood, dairy etc. [7]. The global competitiveness of Irish market needs technology like cloud, IoT, robotics etc. to be used in an effective way to increase production and efficiency [3]. According to Teagasc Foresight report 2035, digital automation in Irish agriculture is expected to increase and will help in increasing production and efficiency [3].

There are many technical factors that drive the adoption of cloud technology on the farm. The ability of cloud technology to integrate with IoT and Wireless Sensor Network can be used in a different application like soil monitoring, humidity, temperature, etc. Land records automation, Weather forecasting, and high storage facility are other features that aid farmers [23]. According to Hristoski et al., the use of cloud-based FMS is increasing in agriculture and estimates that it would reach USD 2.71 billion by 2022 [24]. The social websites have a significant role in communication with farmers for new technology. Twitter and Facebook are the common media for farmers working in the field. AgChat on Twitter and farmers groups on YouTube play an important role among farmers [4].

The Internet of Food and Farm is a program to encourage the use of IoT in the farm by 2020. Besides a vision, this program also aims at research and technological development in agriculture. The other objective of this program is to help farmers in decision making and also to ensure solutions to data related issues like security, interoperability, etc. [1]. Ireland also had schemes like Knowledge Transfer Program that teach the student and equip farmers with new technologies. The main intention of this program is to make farmers' multi-skilled on the farm and to educate them to utilize different technologies like GPS, weather prediction; Computer-based imaging, robotics etc. [3]. "National Digital Farming Test Bed (NDFT)" is another program by Teagasc to encourage young farmers with cutting edge technologies and adoption of digital technology on the farm [3]. "Targeted Agricultural Modernisation Scheme II (TAMS II)" is a scheme from the Irish government to encourage young farmers to use up to date technology in their farm by providing grants of $40-60 \%$ on the technology used [25]. 


\subsection{Adoption Model}

According to Cavallo et al., innovative technology users in farmers are broadly classified into three categories, the "Unwilling", the "Willing-cultural", and the "innovative-Owner" [26]. The "unwilling" categories are usually small holder farmers and they have no interest in new technology. However, the "innovative owner" group of people are more likely to use new innovations and run larger farms. They are familiar with the internet and are ready to invest in new technology. The "willing" group are aware of the new innovation but do not have enough money to upgrade or the available technology might not be suitable to smaller farms [26]. According to the same source, technological innovation improves comfort and safety, and the innovation on farms are mostly associated with larger farms [27]. According to Cavallo et al., age has a variable effect on the adoption, but young farmers are most likely to embrace technology. Whereas, there are cases where old farmers are most likely to adapt to technology [28].

Technology Acceptance Model (TAM) is the theoretical model of Ex-Ante [29]. TAM explains the behaviors of the user's acceptance in using a computer model. The model introduced two factors Perceived Usefulness (PU) and Perceived Ease of Use (PEU). PU means the degree of acceptance of the user ready to work on a system that benefits them. PEU is the extent to which the user feels the system is effortless [29]. According to Pierpaoli et al., TAM is a suitable method to understand the attitude of adoption of users [30].

The success of any new precision agriculture technology depends upon PU and PEU. However, the addition of these two features will help to understand the attitude of adoption of users and is known as the Ex-Ante model. The attitude to use any new technology directly depends on cost. High cost on technology would affect the loss of users in utilizing new technology [30]. The Smart-Akis research on SFT adoption in the European countries suggests that demographic does not have any effect on the adoption of technologies. From the research, the farmers are found to be positive towards its usage. Moreover, the report suggests that costs, knowledge about SFT or infrastructure are the main barriers towards the adoption of SFT [31]. According to Pierpaoli et al., non-adopters do not have an ample skill to manage new technology. PU and PEU over using any technology is effected by cost and also people's ignorance on the low-performance level of technology they use [30]. Timely service, demo and the free trial of new technologies are always encouraged by users [30].

\section{Materials and Methods}

\section{Methodology}

The research was based on the impact of CC and smart farming on the Irish farms. Surprisingly, it was difficult to find the respondents for this research. Respondents were approached with the help of agricultural organization of Ireland, social media like Facebook, LinkedIn, Twitter and direct visit to farms. All data protection rules were followed strictly. Snowball sampling method was used to find the respondents. In this method, the participant will help to find other respondents for the study. A total sample of $32(n=32)$ respondents were received for the research. The study followed the mixed methodology and is accomplished by survey and interview (see Appendix A and B). The survey was done through Google forms and the survey was made possible by sharing it in a Whatsapp group of farmers with the help of people contacted through social media. The recorded interview data was transcribed with the help of MAXQDA, qualitative analysis software. The data was structured on the basis of the nodes created in the software and thematic coding and manual analysis. 


\section{Results}

\subsection{Survey}

\subsubsection{Age, Education and Farm}

A total of 32 responses were received for the survey. The entire respondents were farmers from different parts of Ireland. The participants were of different age groups and doing diverse types of farming. Out of the 32 responses, 7 were females and 25 were males. The data collection process was followed under the standard guidelines. Every subject informed of the cause and consequence of the survey and they have signed the consent form. The participation was voluntary and they could quit any time as per their choice. The educational background (Table 1) and age group (Table 2) of the respondents were recorded. The correlation between education and age group is 0.542 and this shows a moderate positive correlation between age group and education.

Table 1. Educational background of the respondents.

\begin{tabular}{cc}
\hline Education & No. of Respondents \\
\hline Primary & 1 \\
Lower Secondary & 1 \\
Upper Secondary & 3 \\
Third-Level Non degree & 6 \\
Third-Level Degree & 16 \\
Post Graduate & 5 \\
\hline
\end{tabular}

Table 2. Age group of the respondents.

\begin{tabular}{cc}
\hline Age Group & No. of Respondents \\
\hline $18-24$ & 6 \\
$25-44$ & 18 \\
$45-64$ & 6 \\
Above 65 & 2 \\
\hline
\end{tabular}

In Figure 1, the $y$ axis denotes age group and values from 1 to 4 which signify different age groups such as 1 for 18 to 24,2 for 25 to 44,3 for 45 to 64,4 for 65 plus. $x$ axis denotes the Education level and values 100 to 105 which stand for 100 for Third level non degree, 101 for Third level degree, 102 for Post graduate, 103 for Upper Secondary, 104 for Lower Secondary, 105 for Primary. Interestingly, most of the young people who participated were Third level degree holders and more than $75 \%$ of young people in the survey who adopted Information Technology were highly educated. 


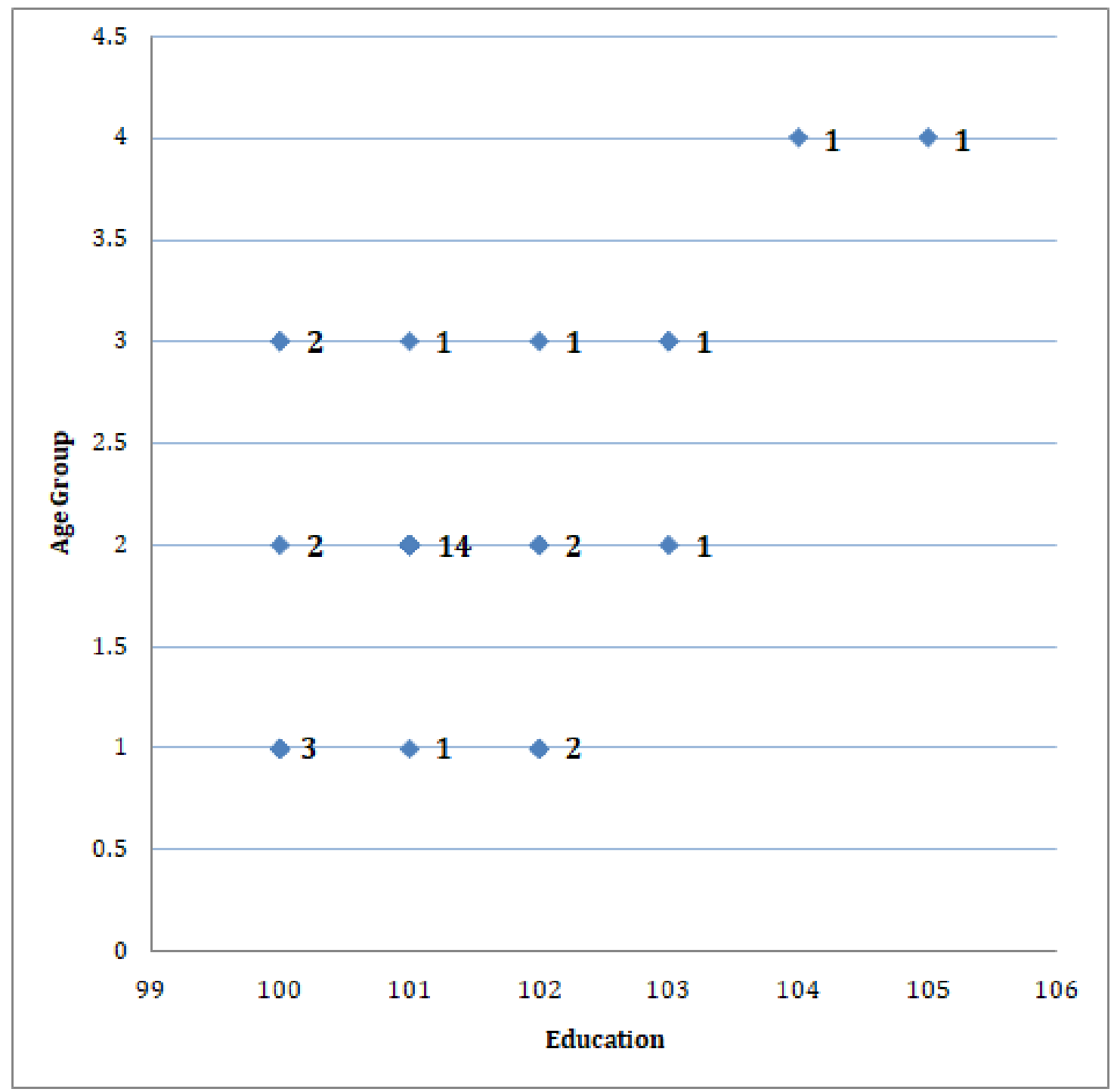

Figure 1. Scatter plot graph between education and age group.

From total subjects, more than $60 \%$ of the respondents were completely dependent on farming while others (37.5\%) are doing farming part-time. Moreover, $28.1 \%$ of the respondents followed mixed farming (Type of farming which involves both the growing of crops and the raising of livestock) while $71.9 \%$ were not. $56.3 \%$ of the participants in the survey were dairy farmer while the least $(12.5 \%)$ were sheep farmers as shown in the Figure 2. 


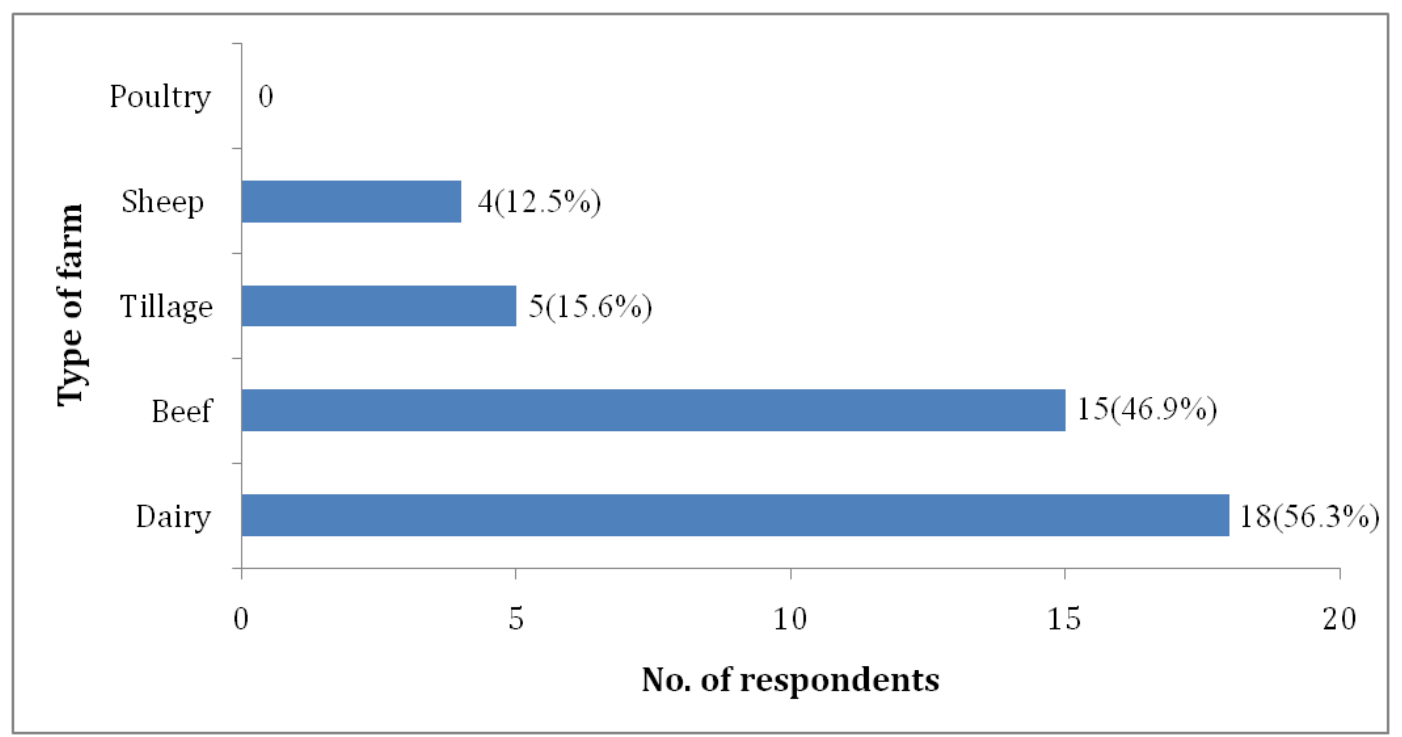

Figure 2. Types of farms.

\subsubsection{Farmers' Attitude Towards Using Information Technology}

One of the important questions in the survey was "Will the influence of information technology in farms make its maintenance easier". Unexpectedly, $96.9 \%$ believed that IT would make farming easy. While 3.1\% said no, as shown in Figure 3.

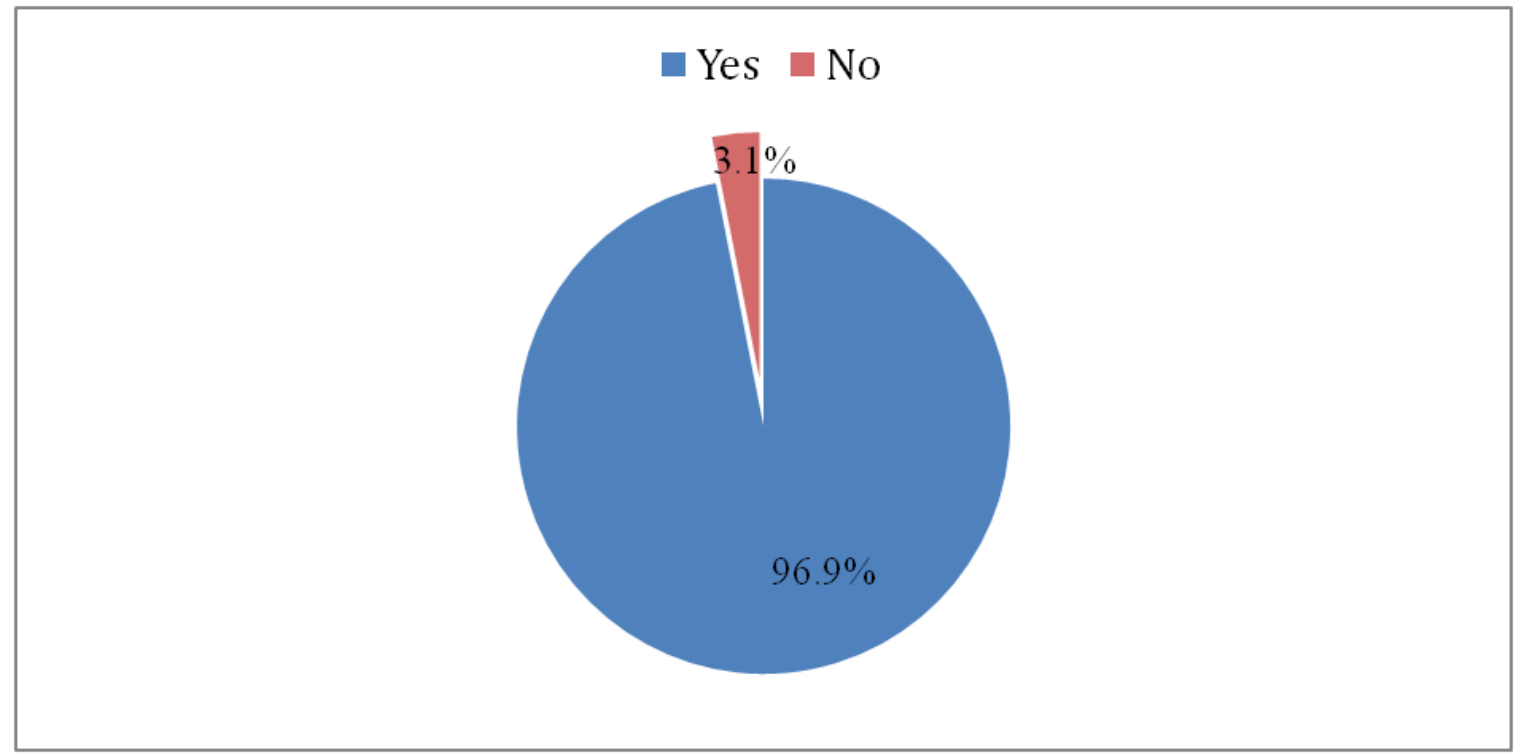

Figure 3. Responses of the farmers as to whether or not IT provides easier farm management.

The question regarding the use of IT by the farmers in Ireland led to the division of the respondents into two groups. It was observed that $62.5 \%$ of respondents were using some kind of IT in their field and were named as "adopters" while the remaining 37.5\% does not use any kind of technology and called as "non adopters" as shown in Figure 4. 


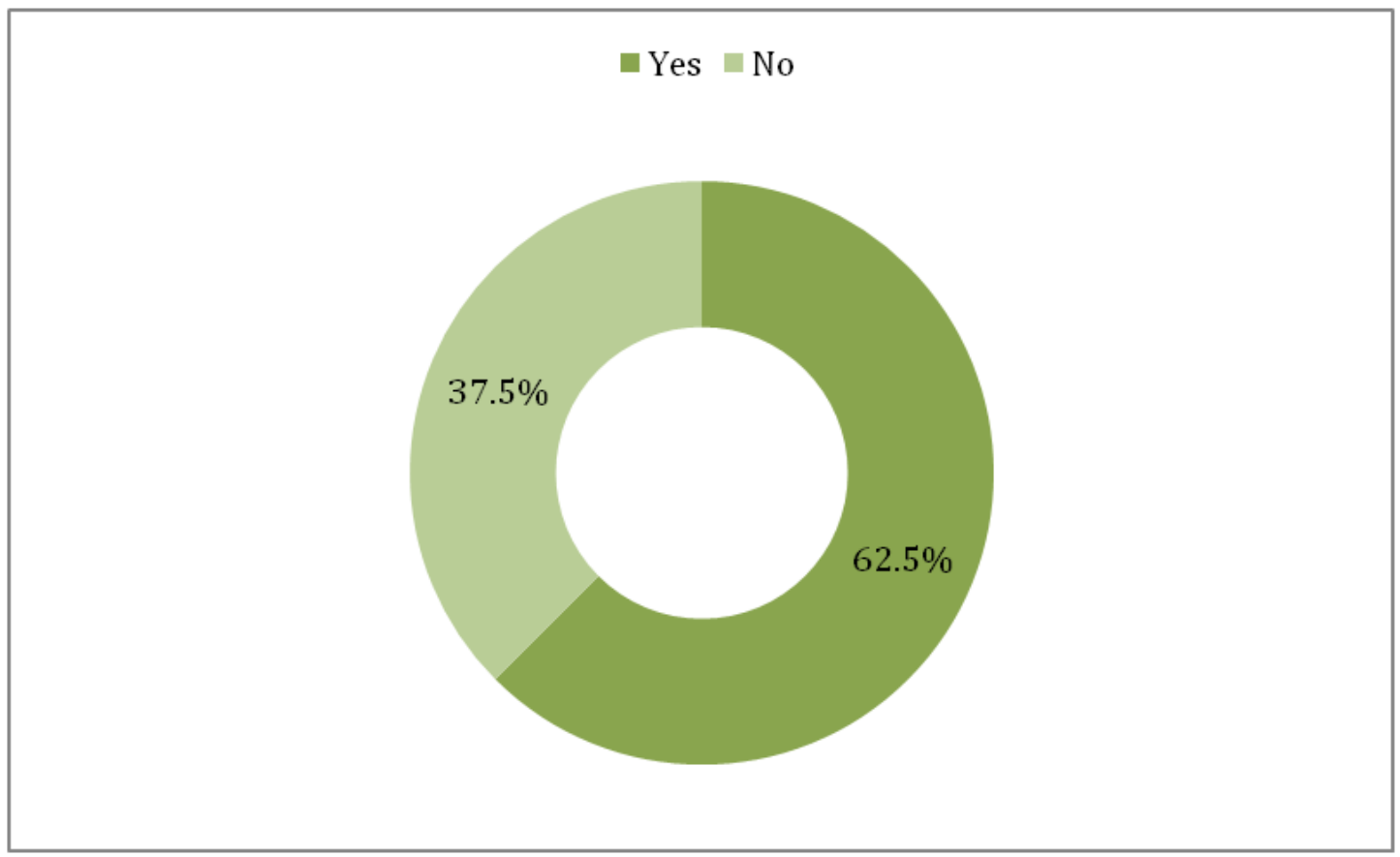

Figure 4. Percentage of the farmers used IT technologies on the farm.

The following were the common Information Technology used in Ireland based on the responses from the participants attended in the survey as shown in Table 3.

Table 3. Technology used by the respondents.

\begin{tabular}{ll}
\hline Technology Used by Farmers & Technology Used \\
\hline Dairy & - Grass management Decision support system and software \\
& - Application used for registering calf births, moving animals etc. \\
& - Remote signals soil monitor \\
& - Software for managing the herd, grass and accounting on farm \\
& - Software for area measurement for grass allocation \\
& - Remote camera \\
& - RFID \\
& - Activity meters \\
& - Farm mapping \\
& - Soil temperature sensor \\
& - Diet feeder technology \\
& - Software for managing the herd, grass and accounting \\
\hline Beef/Sheep & - Weather apps \\
\hline Arable & - GPS in fields \\
\hline
\end{tabular}

The adoption was observed more in the Dairy farming especially between the age group 25-44 year as shown in Table 4. However, adoption was good among the farmers using mixed farm as well. It was found that out of the 20 responses of farmers who used some kind of IT, four of them were part-time farmers as well. 
Table 4. Farmers who adopted Information Technologies.

\begin{tabular}{llllll}
\hline Age & \multicolumn{2}{l}{ Gender } & \multicolumn{2}{l}{ Farm } & \\
\hline & Male & Female & Dairy & beeflsheep & Arablee \\
\hline $18-24$ & 1 & 2 & 3 & 1 & 0 \\
$25-44$ & 10 & 1 & 9 & 1 & 1 \\
$45-64$ & 1 & 0 & 1 & 1 & 0 \\
\hline
\end{tabular}

In contrast to this, the non-adopters were asked about their opinion about the adoption of any information technology in future and the results showed major portion (58.3\%) like to adopt some kind of information technology in their farm while $25 \%$ was skeptical about adopting it and a small percentage (16.7\%) had no plan to adopt technology in the future as shown in Figure 5.

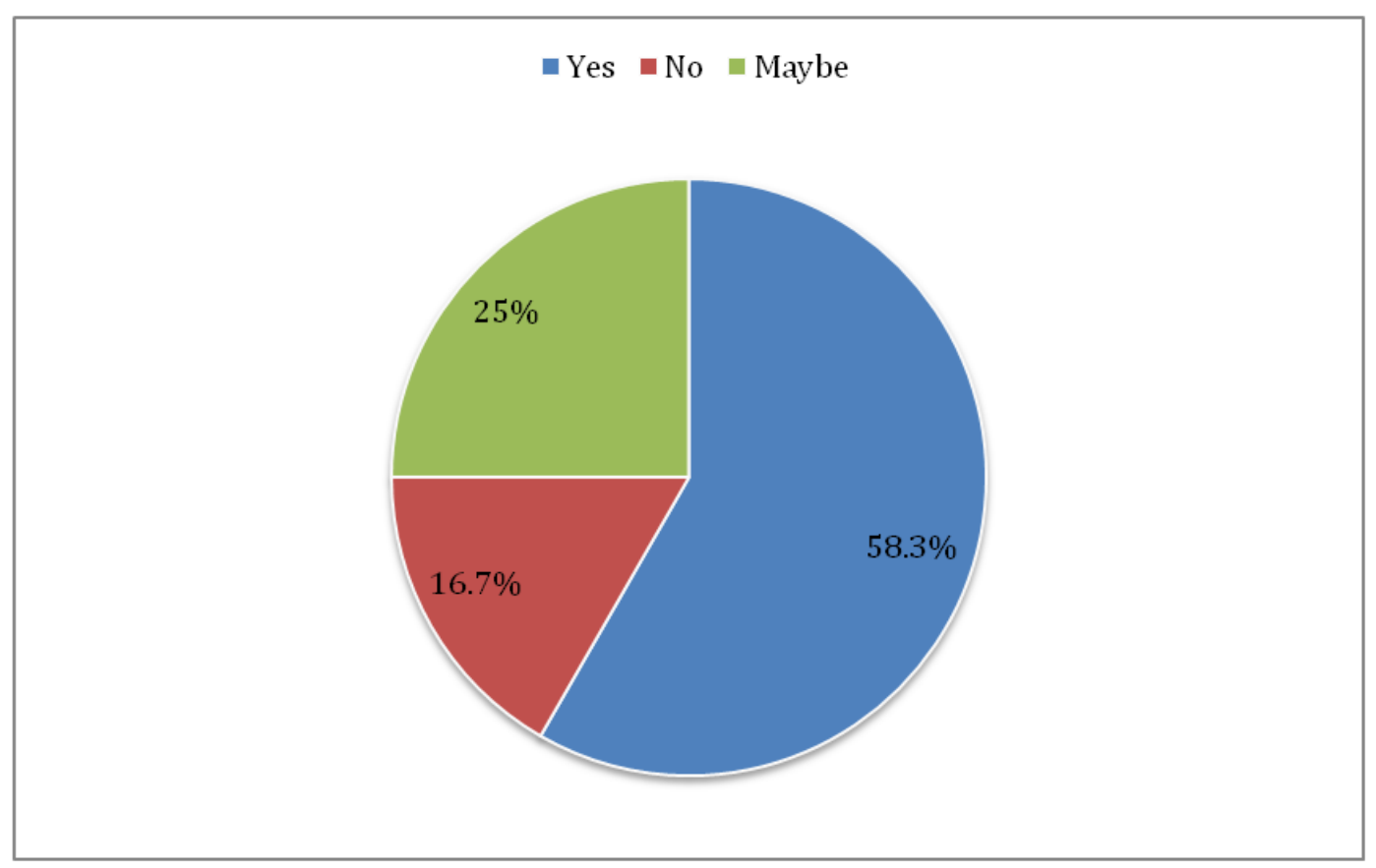

Figure 5. Adoption plan of information technology among non-adopters in future.

However, the same percentage of non-adopter farmers as in Figure 3 were likely to use and learn farming related application for controlling and monitoring different areas on farms such as tracking all the transaction, weather, soil, crop/animal information of their farm through a mobile platform.

The respondents were asked for their opinion on digitalizing the agriculture and most of the farmers $(71.9 \%)$ picked yes for digitalizing agriculture. In contrast to it, $18.8 \%$ of farmers were not sure about it and a minimal section of farmers $(9.4 \%)$ were not ready to accept the change as shown in Figure 6. 


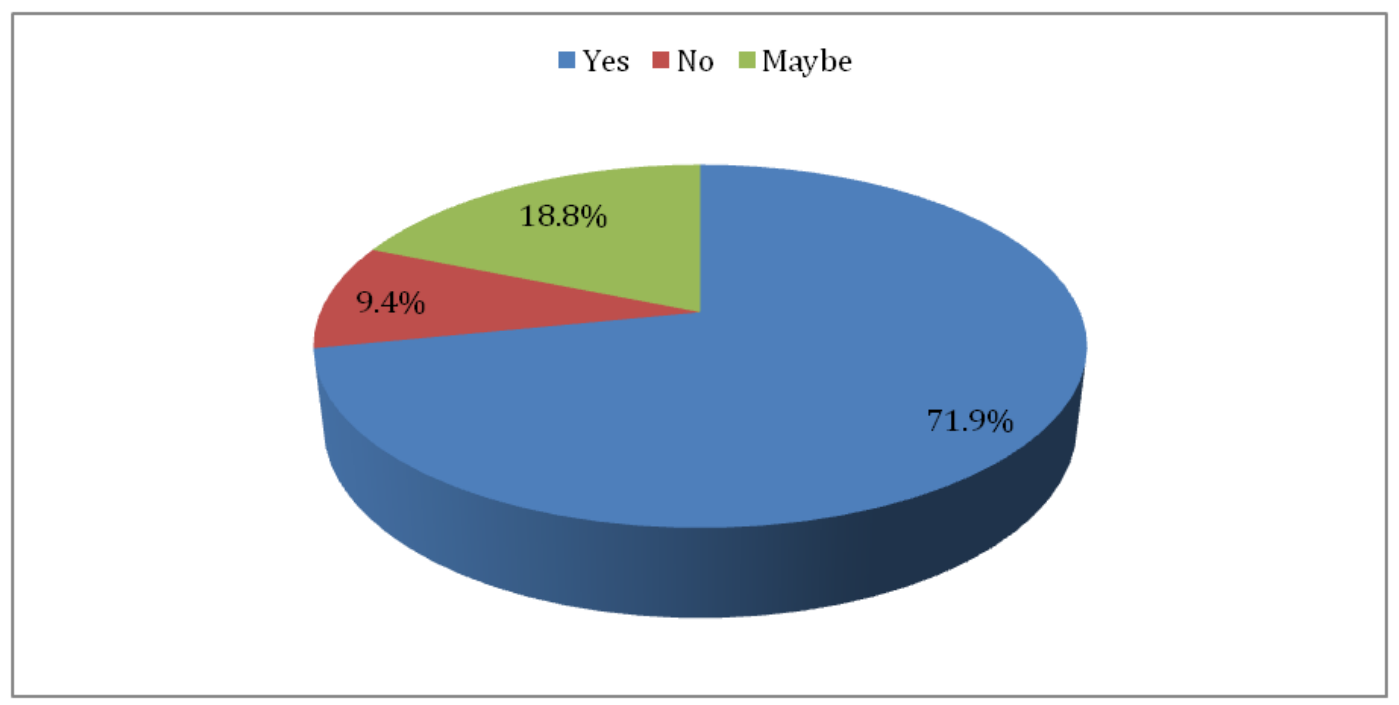

Figure 6. Respondents willing to partake in technology driven transformation in agriculture.

\subsubsection{Perception of Farmers Towards Using Cloud Technology}

The adopters of information technology were asked whether they use any CC technology in the farm. More than two-thirds (70\%) of farmers used some kind of CC technology on their farm and the remaining 30\% did not use such technologies as shown in Figure 7.

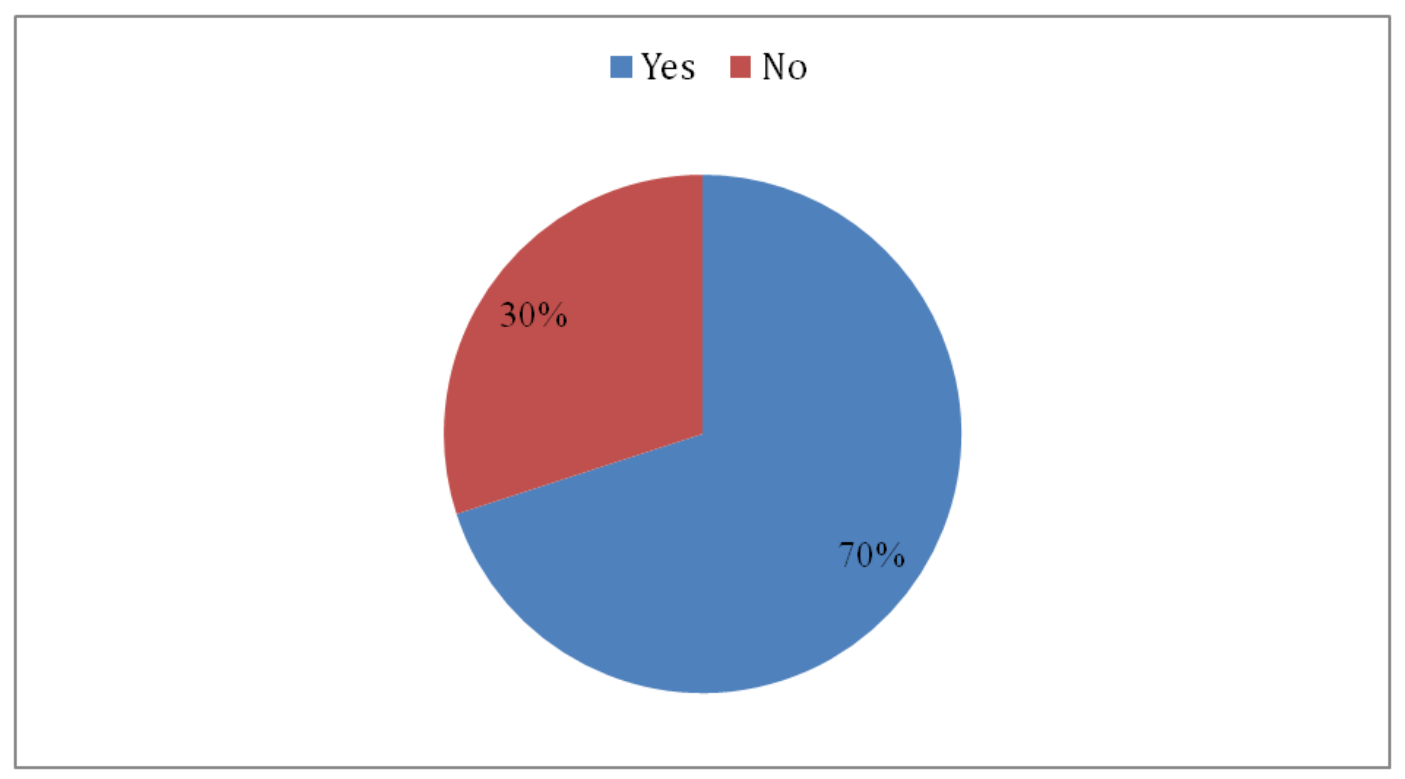

Figure 7. Respondents using Cloud Computing technology on. their farms.

Most of the farmers used CC technology for recording the animal data and stock. Other farmers used it in applications like GPS for fertilizer, grass management, financial budgeting etc. as shown in Figure 8. 


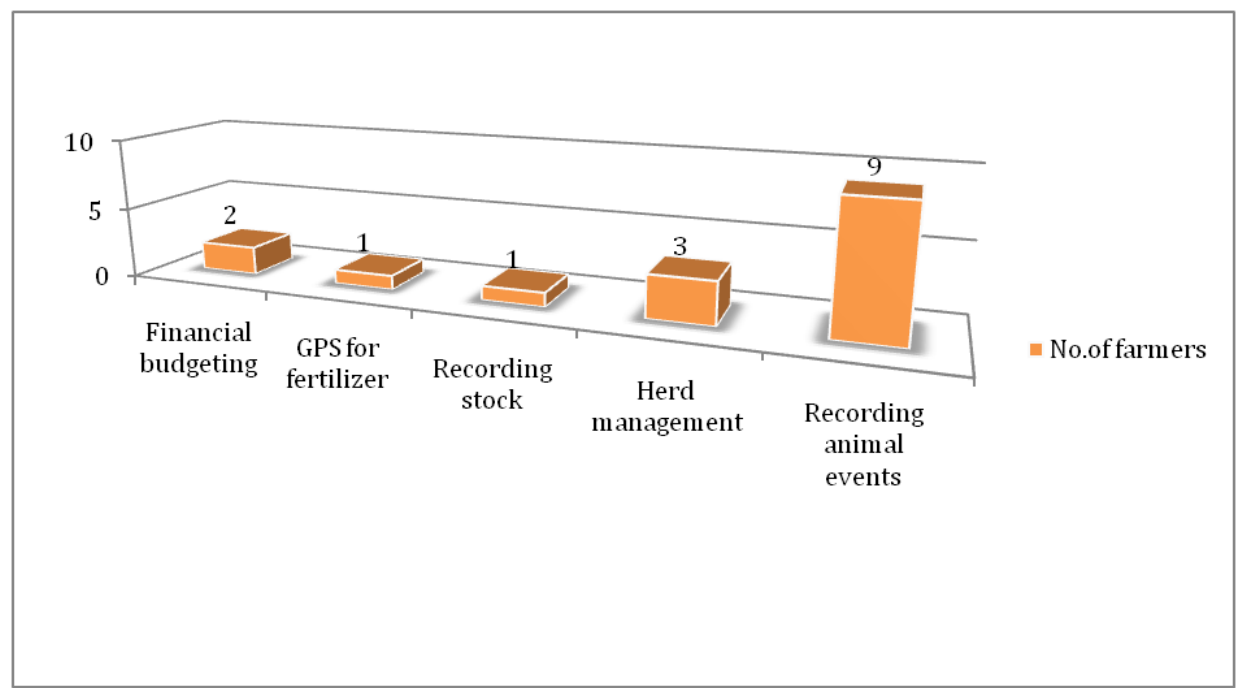

Figure 8. Purpose of using Cloud Computing.

Analysis was also made among the farmers who adopt technology on using any farming application in their smart phone. Eighty percent of farmers use some kind of application in their Smart phone as shown in Figure 9.

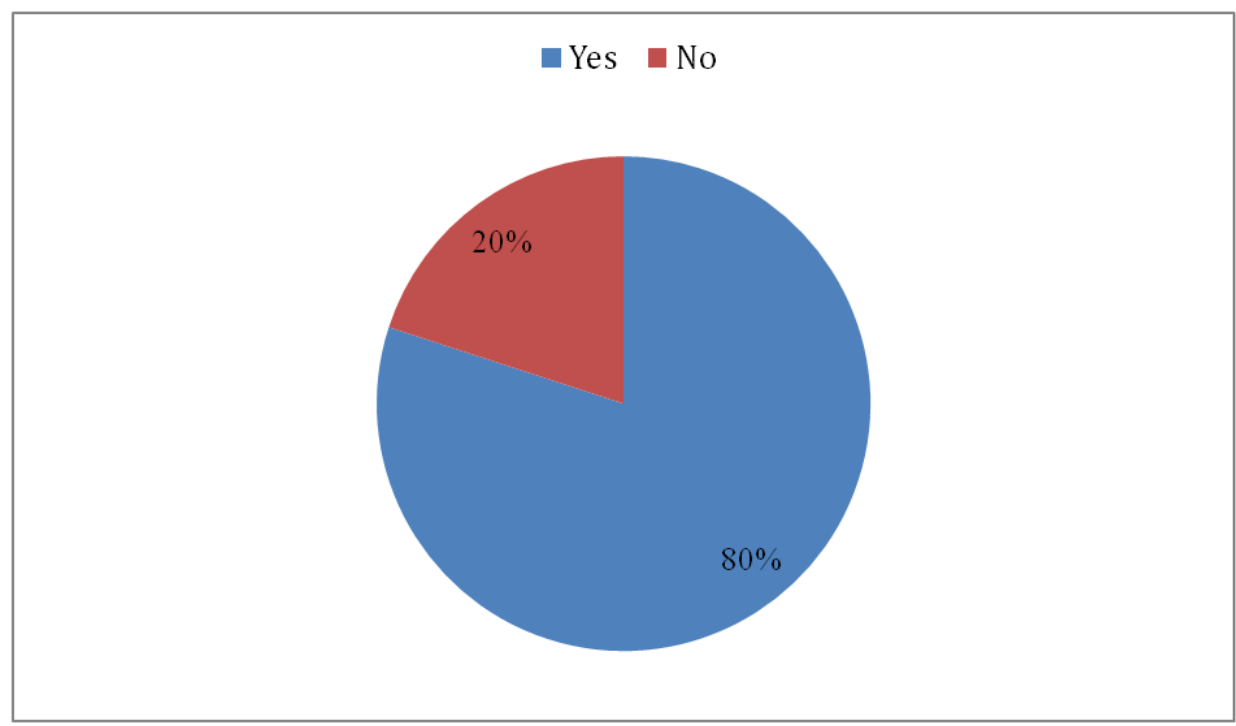

Figure 9. IT applications in smart phone for farm.

Most of the dairy farmers used smart phone applications for farming applications and a major portion of the users were between the ages 25-44, as shown in Table 5.

Table 5. Demographic smart phone usages on Farm.

\begin{tabular}{cccccc}
\hline Age & \multicolumn{2}{c}{ Gender } & \multicolumn{3}{c}{ Farm } \\
\hline & Male & Female & Dairy & Beef/Sheep & Arable \\
\hline $18-24$ & 1 & 2 & 3 & 1 & 0 \\
\hline $25-44$ & 10 & 1 & 9 & 1 & 1 \\
\hline $45-64$ & 1 & 0 & 1 & 1 & 0 \\
\hline
\end{tabular}




\subsubsection{Farmer's Technological and Information Seeking Behaviour}

Most of the farmers (70\%) who adopted some kind of information technology kept the records of farming details with the help of software and book/diary. However, 30\% of farmers only used software to keep the farming details as shown in Figure 10.

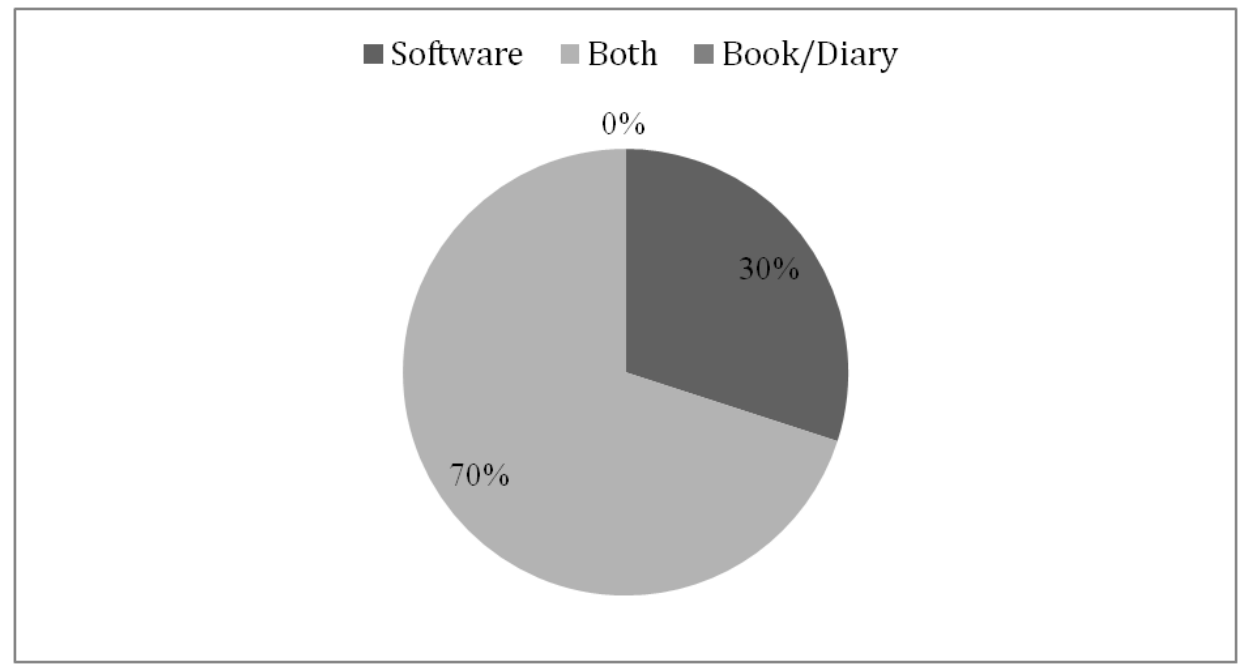

Figure 10. Record keeping methods of the participant farmers.

The farmers who embraced information technology were asked about which medium they used to access information through any digital platform. Fourteen out of 20 respondents selected YouTube, Whatsapp, Facebook and Farming news portal as the main intermediate to get information about new technology as shown in Figure 11. However, $45 \%$ of respondents found Twitter as another source of information. While a small percentage $(1 \%)$ of people found information through Farmers Journal App, Google Plus and word of mouth. Interestingly, none of them seek the help of wikis or blogs to find information, as shown in Figure 11.

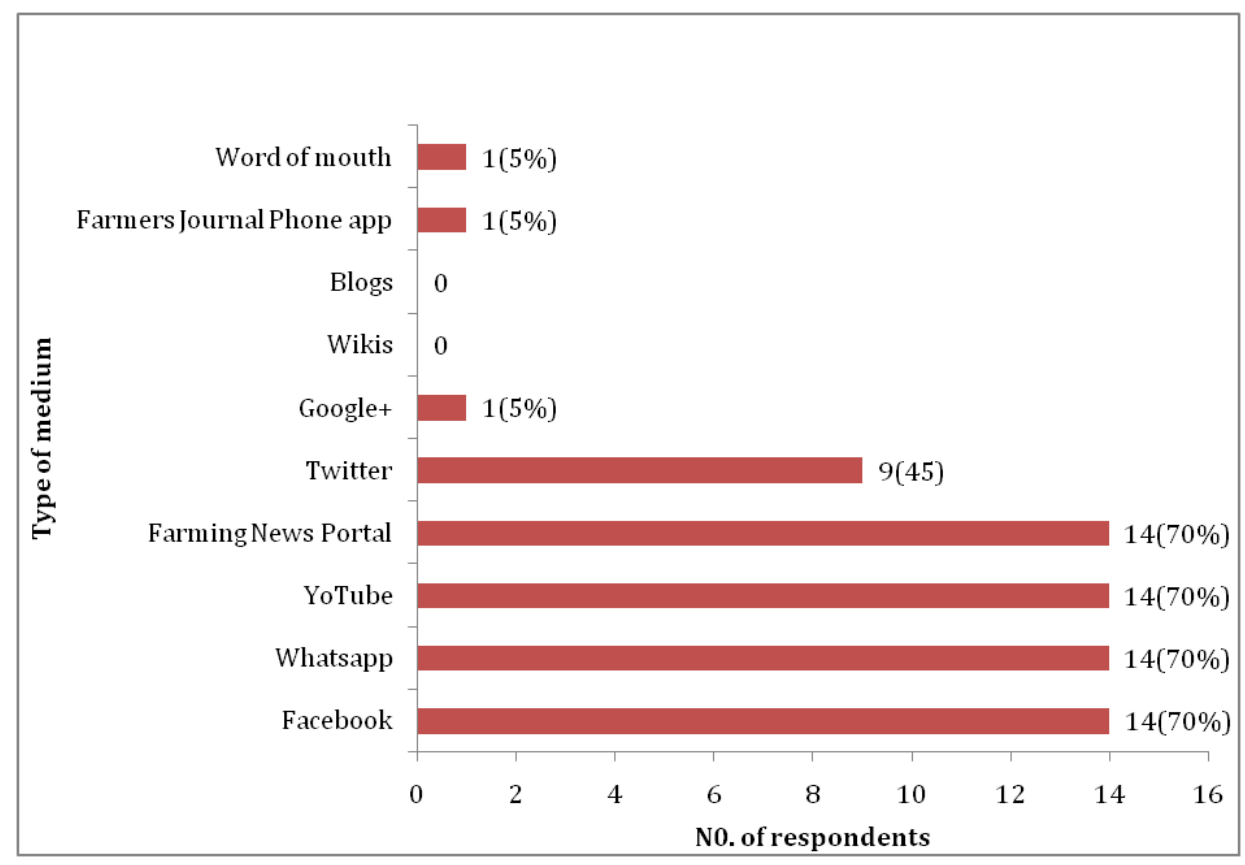

Figure 11. Methods used by the adopter farmers to get new information. 
On the other hand, Non-adopters were asked the same question about updating new technology, considering their use of limited usage in digital platform. Nine out of 12 farmers found the paper as the main medium to update any new technology. Moreover, another major portion (7) updates knowledge through other farmers as shown in Figure 12. However, a very small percentage of farmers find information through digital platforms like digital news (3), YouTube (2) and Twitter (1). However, two participants find Television (TV) as a source of information as shown in Figure 12.

\subsubsection{Farmers Perception of CC Potential to Deal with Challenges}

The adopter farmers were asked to pick the area of preference where more applications based on farming need to be developed and the result showed that $55 \%$ of farmers need applications for Accounting on farm, $45 \%$ need in herd management while another major portion (50\%) claims that there is a need for applications in all the areas such as supply chain, herd management, accounting and precision information (like weather, humidity etc.) as shown in Figure 13.

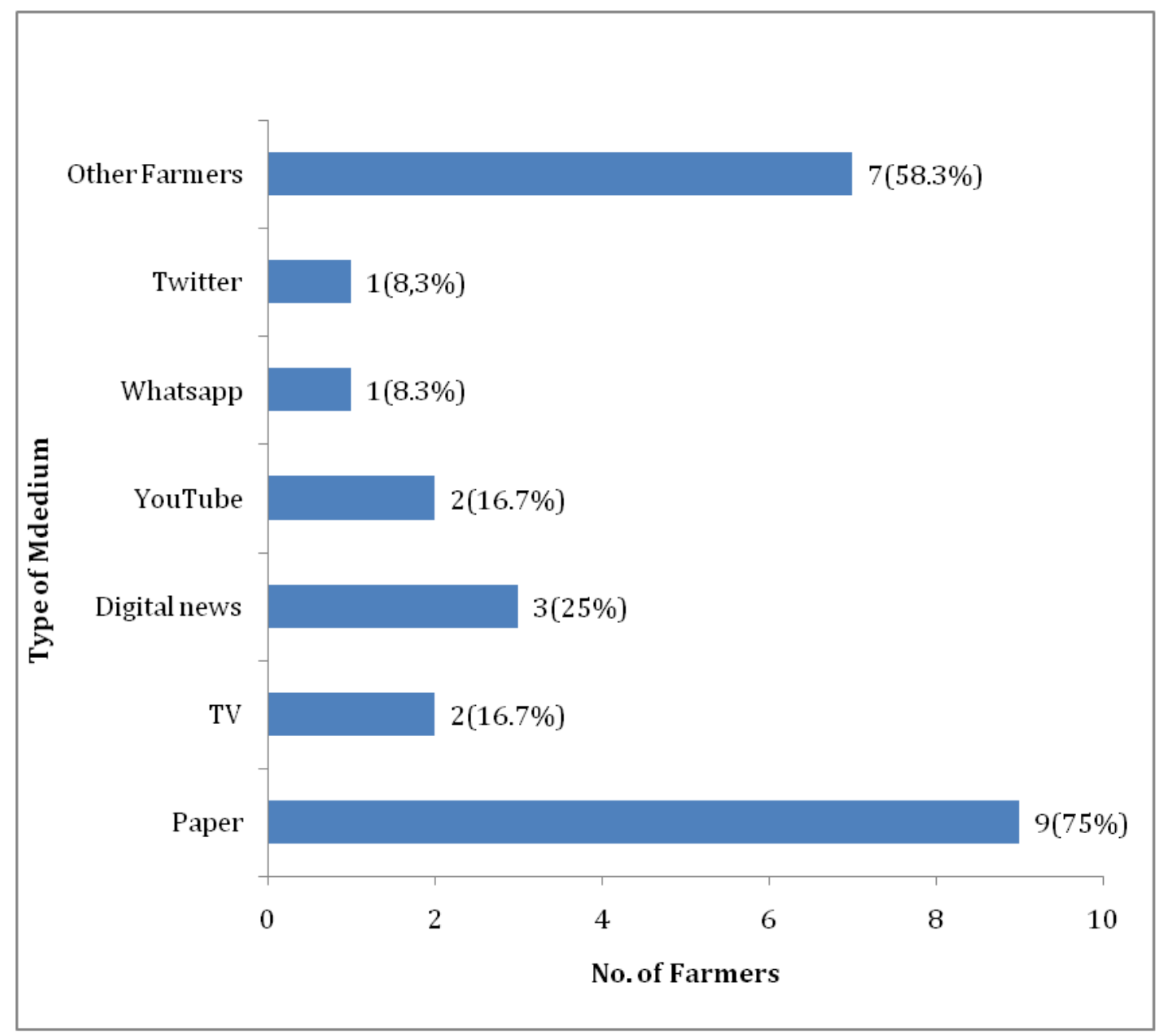

Figure 12. Methods used by the non-adopter farmers to get new information. 


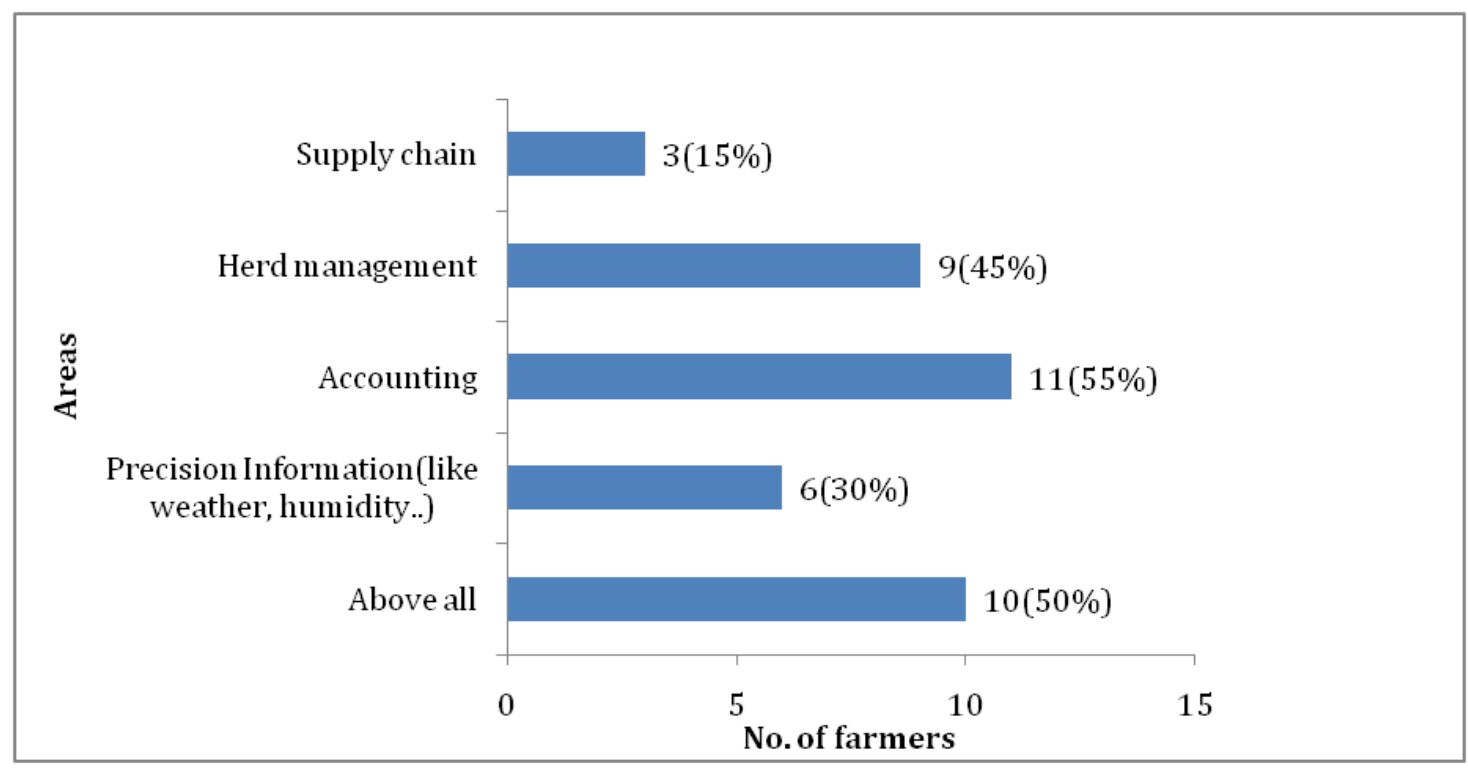

Figure 13. Farmers preference on agriculture related mobile application.

There were difficulties in adopting any information technology among the non-adapter farmers that could also be relatable to the already existent users that could help in enhancing the user experience, as shown in Figure 14. However, more than $65 \%$ of farmers felt that small farm size was the primary reason while another major portion found difficulty in the initial investment (50\%) and Complexity to use (41.7\%). Other issues like uncertainty about the value of the technology used (33.3\%), inappropriate technology on farm $(16.7 \%)$, data sharing $(16.7 \%)$, lack of knowledge about the technology $(8.3 \%)$ and the difficulty of using technology among older farmers ( $8.3 \%)$ make the use of technology challenging.

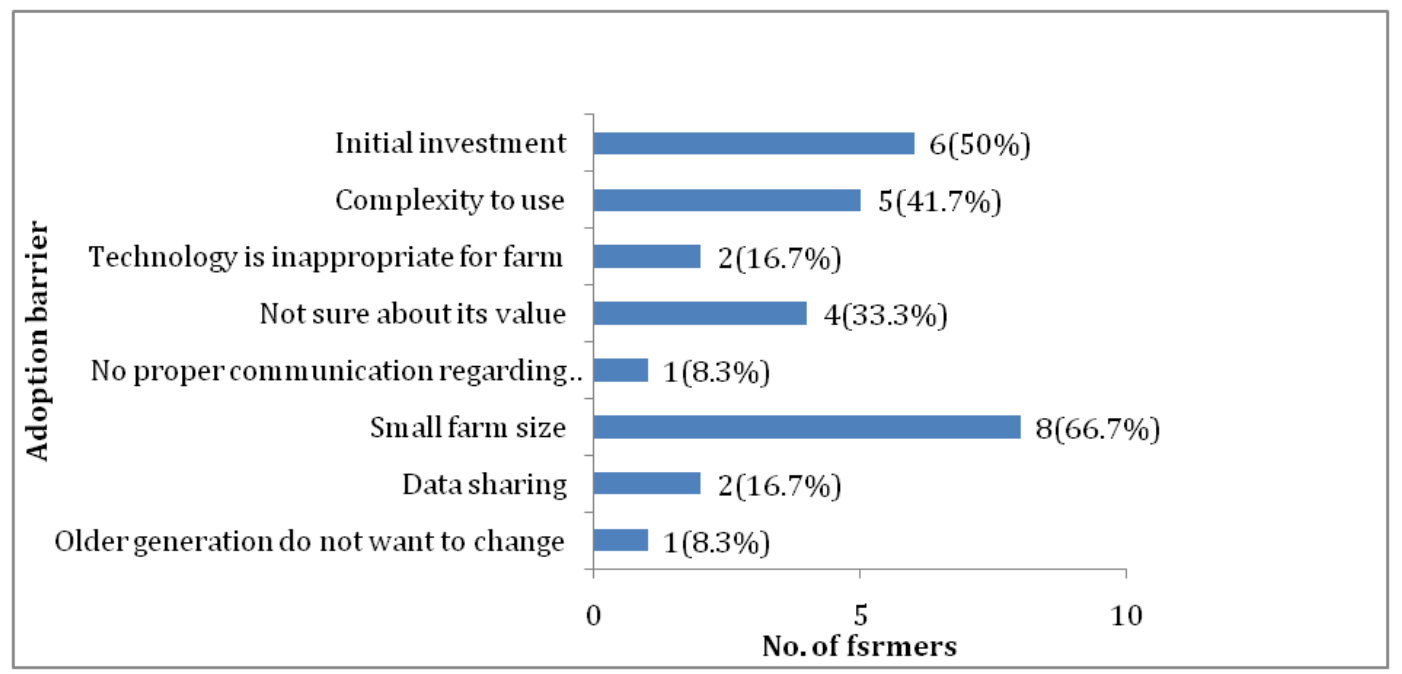

Figure 14. Major adoption barriers among non-adopters.

\subsubsection{Communication between Farmers}

The response from the Irish farmers revealed that more farmers prefer group meeting as the common medium for communication. However, social media is the next medium where most of the farmers from Adopters communicate followed by E-mail, SMS, Intranet, paper/magazine. While Non-adopter farmers use Email as the second most medium to communicate with other farmers followed by social media, E-mail, SMS, and other medium like phone calling, in person etc., as shown in Figure 15. 


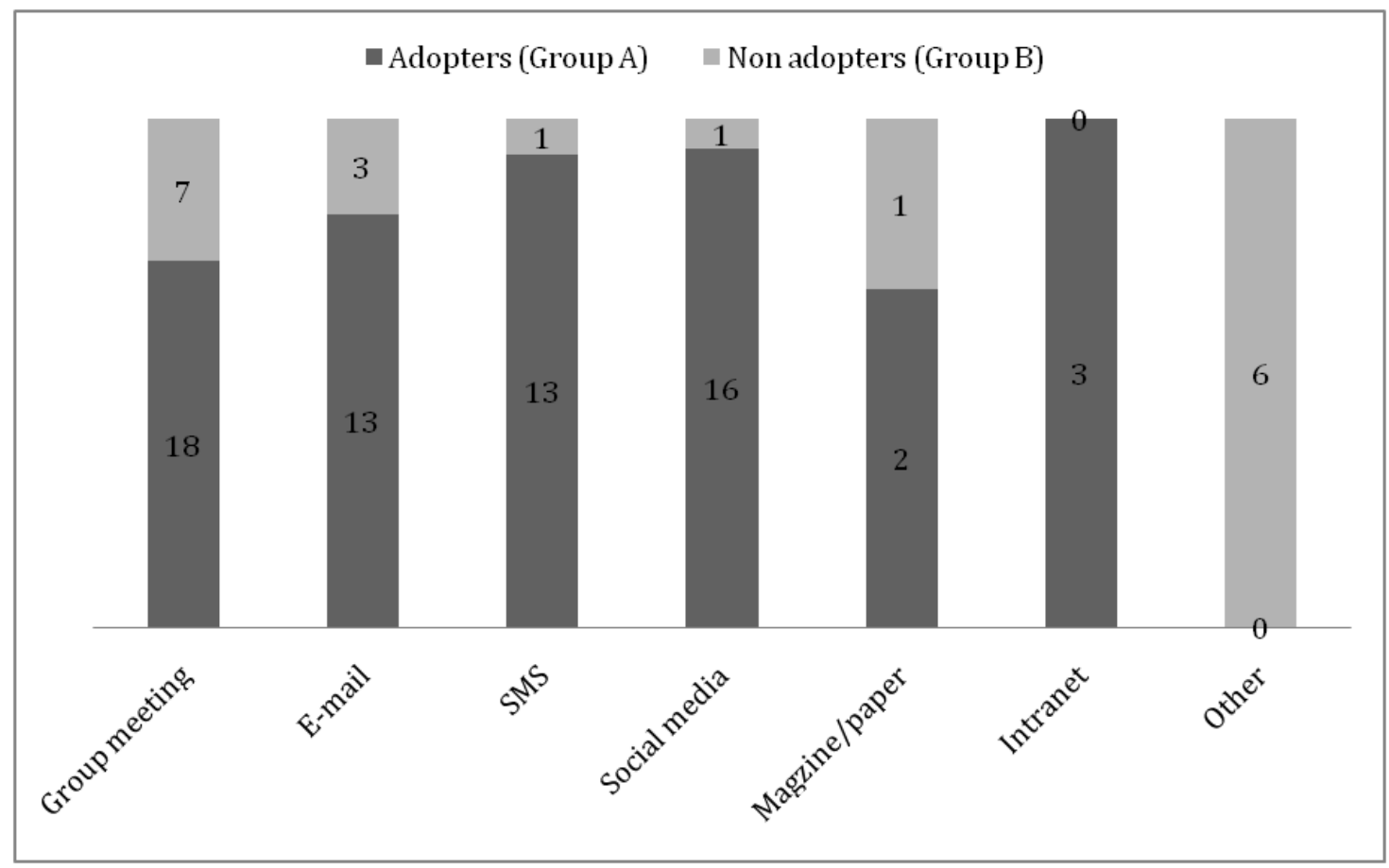

Figure 15. Communication medium between farmers.

Farmers were asked to grade the communication with other farmers in Ireland. However, results showed that communications were more prominent among the farmers who adopted some kind of technology, while it is the average between non-adopter farmers as represented in Figure 16.

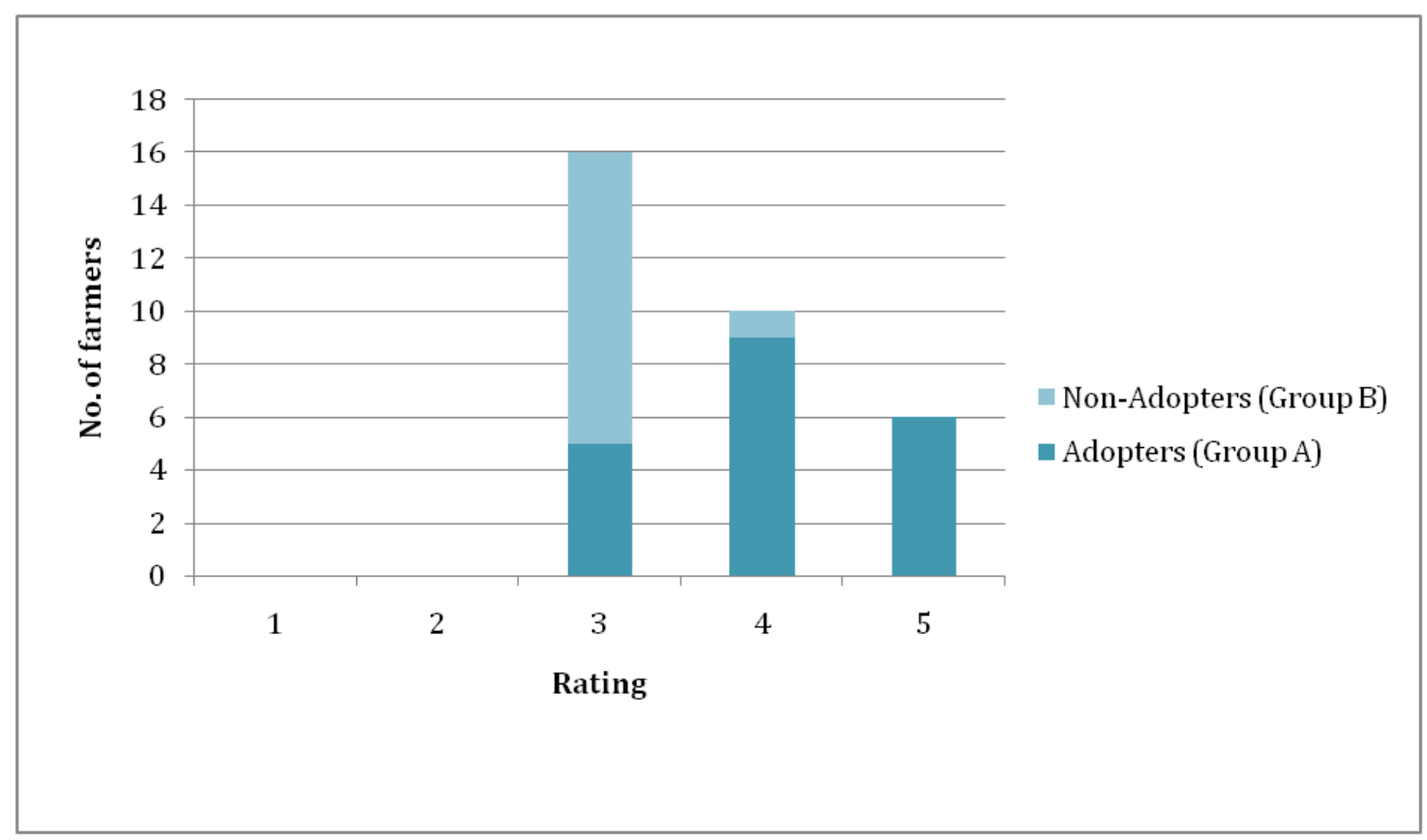

Figure 16. Rating for communication. 
This communication diversity was also impacted in the opinion of farmers in sharing the information with other IT technologies. The adopters were ready to share information for the agricultural development. Although, a major portion of non-adopters show interest in exchanging information but another portion of non-adopters are skeptical and not at all interested in sharing information to companies as shown in Figure 17. It shows the farmers were ready to adapt new changes. The change in the information knowledge can bring a lot of changes.

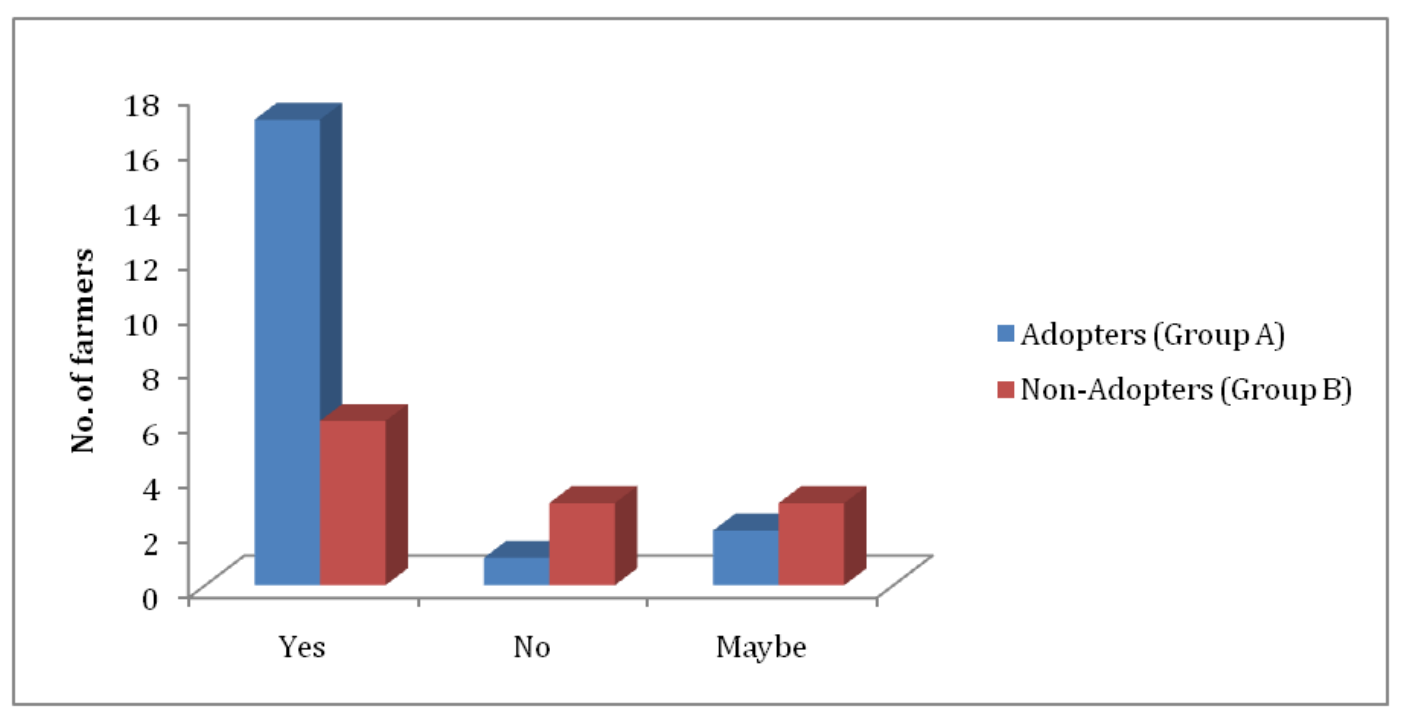

Figure 17. Information sharing with companies.

\subsection{Interviews}

The structured interview pattern was followed, the same questions were asked to all the participants and the respondents were divided into two groups based on the answers received (Adopters and Non-Adopters). There were six participants joined in the interview and all of them were farmers doing different types of farming. The interviewees were coded as IN and an individual number was assigned for all answers as shown in Table 6.

Table 6. Information about age, gender, education, farm of interviewees.

\begin{tabular}{cccccc}
\hline No. & Age & Gender & Education & Type of Farm & Adaptation of IT \\
\hline IN1 & $45-64$ & Male & Third level non-degree & Mixed (Beef, Arable, sheep) & NO \\
IN2 & $45-64$ & Male & Upper Secondary & Beef & NO \\
IN3 & $45-64$ & Female & Post-Graduate & Mixed (Beef, sheep) & NO \\
IN4 & $18-24$ & Female & Post-Graduate & Dairy & YES \\
IN5 & $25-44$ & Male & Third level degree & Dairy & YES \\
IN6 & $45-64$ & Male & Third level non-degree & Mixed (Dairy, Arable) & YES \\
\hline
\end{tabular}

\subsection{Overview of Interview}

All farmers had a positive attitude towards using Information Technology on their farm. Most of them are ready to accept technology if it is profitable, making their life easier and less complex. The perception of farmers was different towards using CC on their farm. The ones who already adopted take it as a tool that can make management easier. They make use of this for recording stocks and also for some off-farm practices like paper work. However, the non-adopters were not fully aware about CC but they believe that any technology using a computer is hard for them and cannot be embraced in their generation. However, the farmers who like to adopt such technology on their farm had no internet in their area. 
All the farmers expressed that CC has the potential to bring changes in Irish farms. They believe that it could increase the efficiency, animal welfare and bring environmental awareness among farmers. There is still lack of availability of software in the herd management and accounting management for Irish farmers. All the farmers believe that usage of CC will not affect the role of farmers instead it makes them a better manager. However, Non-adopters believe that it could affect the younger farmers but not in their generation because of their lack of interest in using new technology and they do not like to lose the pleasure of farming. Most of the farmers find cost, data protection, unsuitability of technology in their farm and complexity to use the technology as the main reason for adoption. All the farmers believed that the uptake of technology in Ireland is slow. The factors like small farm size, ageing, low income, and lack of attitude of Irish farmers on perceiving new information are the major reason pointed out by respondents for slow adoption of technology in Ireland among farmers compared to other countries. The farmers also suggested some ways to improve the present system. They were: making use of discussion group, perfect utilization of media to inform farmers, educating the younger generation on the importance of agriculture and new technology, reliable source of information and informants, cost reduction and providing grants to use new technology on farms. Knowledge transfer is a discussion group program organized by DAFM. Thirty percent of farmers interviewed are not aware of this program while others find this very helpful to share information. All farmers said that it is important to make young people take over farms. Even though some farmers believe that technology could attract them, others believe that it is the income that determines the participation of young farmers.

\section{Discussion}

The primary objective of this research wasto find the reason for slow adoption of SFT in Ireland compared to other countries. CC is an SFT and its impact was evaluated for further conclusion of this research. The study was conducted with a sample size of 32 Irish farmers and were selected randomly. Sample size is a limitation of the study due to various reasons such as communication difficulty between farmers, General Data Protection Rule (GDPR) to collect the details among farmers, and also short time period taken to complete the research. However, the research revealed the reasons regarding the adoption barrier between adopters and non-adopter farmers and would suggest the way to improve upon the present system.

\subsection{Determinant for Adoption of Cloud Computing}

The research helps to find the main drivers for adoption. Socio-economic factors like age, sex, and education have an impact on adoption of Information Technology. According to Pierpaoli et al. (2013), age of farmers on adoption varies. It is very difficult to distinguish between the adopters and non-adopters with the age. However, in some cases the young generation is more accepting of new technologies [30]. The response from the survey showed that young farmers in Ireland are adopting Information Technology like CC. The research of Knierim et al. says that demographic factors like age do not have any dependency on adoption of smart farming in European countries [31]. However, the interview with old farmers in Ireland showed a strong reluctance to use new technology due to their lack of interest and strong belief in their traditional farming. Interestingly, most of the non-adopter farmers show interest in accessing CC technology on their farms. According to Keskin et al., farmers with small farms were not able to invest in any new technologies due to low income [32]. Size and perceived ease of use is competitive and contingent factors of Ex-Ante model. Perceived ease of use in TAM model is influenced by other factors like education, support availability, computer efficiency and previous experience in using any technologies [31]. Dairy farmers in Ireland were observed to embrace more new technologies. As stated by Nicole et al., a significant factor that separates adopters and non-adopters is farm size. Adopters tended to have large farms while non-adopters tended to have small farms [33]. In a study conducted in Turkey on usage of precision technology in farms, it was mentioned that 
lack of knowledge on using any precision technology is the main barrier to adopt any technology on farm [34]. On the other hand, small farm size, complexity and ease of use is the reason for non-adopter farmers in Ireland not using any SFT in their farm. One of the farmers said that making the software or mobile application less complex would enhance their usability among the computer illiterate staff members. However, the perception of complexity on use is high among the non-adopter farmers. In addition to the lack of experts available to initiate the learning process among non-adopter farmers is another reason, the response from one of the farmers suggested lack of presence of informants on passing the information to explain its usability. According to Ex-ante model, cost and perceived benefit and usefulness was another factor affecting attitude of adoption. Cost was the main factor that takes farmers away from embracing any technology. Initial investment was a major barrier for the majority of non-adopter farmers. However, a beef farmer said that he was unsure about its value and suitability of Information Technology on his farm. On the other hand, many farmers believes that SFT like CC would increase its productivity but are skeptical about its benefits on their farm. It is also observed that part time farmers are less likely to adapt to CC technology. However, most of the non-adopter farmers had more than one job and they earn less from the farming which makes them concerned about investing in a new technology in which they are not sure about its return of investment. Considering the above factors effecting adoption, the Ex-Ante model of adoption factor among Irish farmers is as shown in Figure 18. However, this study among Irish farmers revealed that infrastructure factors, like absence of internet, also affect the adoption of technology among farmers and are more in the rural area of Ireland. Moreover, data security is another concern of some of the Irish farmers who have already adapted to technology, in order to further improve their farm.

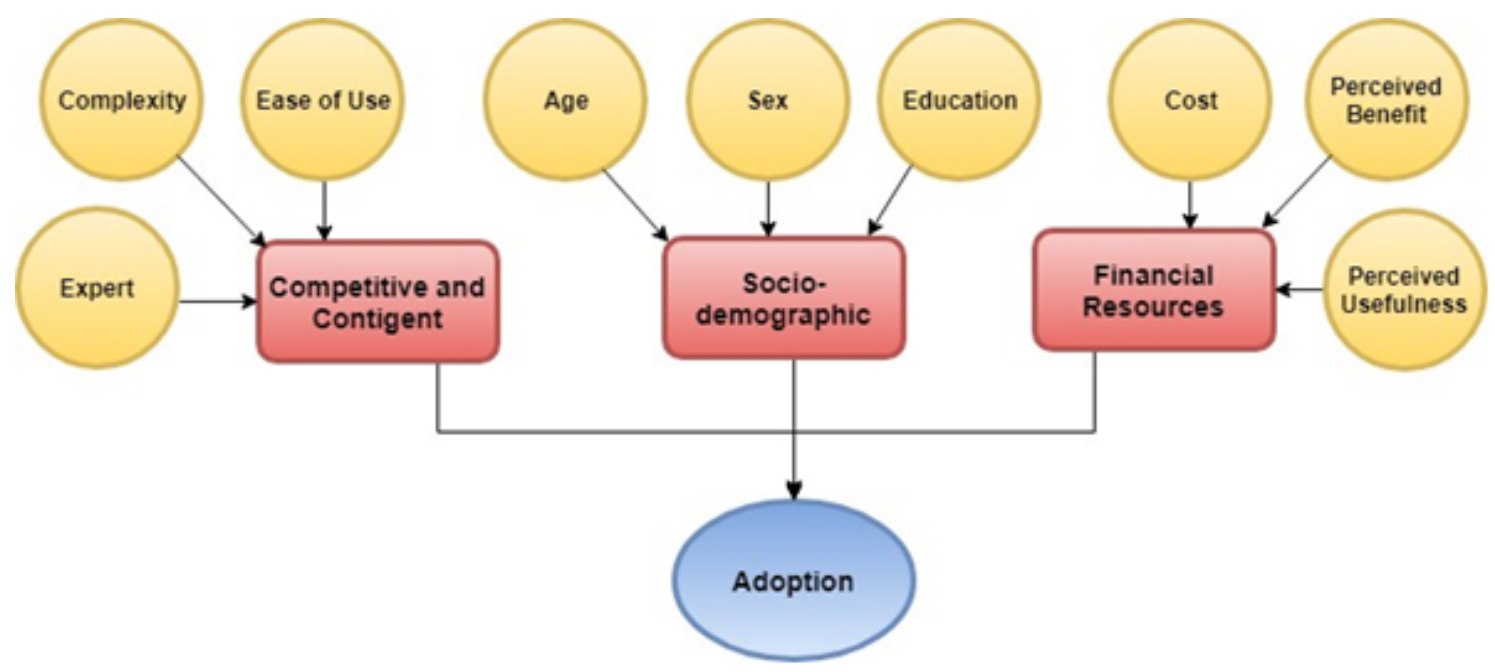

Figure 18. Adoption factors.

\subsubsection{Farmers' Technological and Information Seeking Behavior}

There are a number of alternative methods to seek the information for farmers. The information collected through those mediums enables decision making that support innovation. The source for information depends on individuals. It is a complex process to find a pattern of information seeking behaviour of farmers. The pattern would help in extension of information seeking methods and would help farmers to access the information from the available sources without any error [35]. The survey among Irish farmers shows that the digital platform has a great impact on information seeking behaviour of Irish farmers. YouTube, Whatsapp, Facebook and farming news portal were the main digital sources used by farmers who adopted cloud technology in their farm. The non-adopters 
sought information through the newspaper, contacting other farmers and a small amount of farmers prefer TV and digital platforms to seek the information.

A proper communication channel between farmers is needed for a setup that can enable the information about technology and its updates to circulate between the farmers. Identification of the right communication channel would help to introduce new technology to the farmers and the platform would aid government, researchers and Agro-tech companies to broadcast information. However, the response from the Irish farmers showed that most of the farmers were communicating with each other in the group meeting associated with their farmers' association. A knowledge transfer program introduced by Department of Agriculture, Food and Marine (DAFM) is a discussion group to increase the skill among Irish farmers. According to interviews with farmers in Ireland, non-adopter farmers were not aware of this program. The reasons given by the farmers were that the sharing information was difficult for some farmers as they live in more secluded environments while others suggested that sharing information platforms were not implemented in the best way. Social media, SMS and Email also find great impact on the communication between farmers.

\subsubsection{Cloud Computing Usage among Irish Farmers}

One of the main objectives of this research was to find the rate of usage of SFT among the farmers. Interestingly, more than $60 \%$ of farmers surveyed were using some kind of information technology and out of that $70 \%$ used cloud technology on their farm. More than $70 \%$ of farmers like technologically driven agriculture. Adopters utilize the cloud technology for different applications in their farm like recording animal events, herd management, recording stock, and financial budgeting. However, more than $25 \%$ of females make use of cloud technology. The response from one of the female farmers was that they find useful paperwork related to the farm through mobile platforms and some make use of it in the office for updating information regarding stocks. Most of the farmers are making use of this for off farm practices. However, there are farmers who use IoT sensors like Moocall for cows, an application to record background farm data like PastureBase, RFID tag. However, more than 55\% of farmers who did not use any kind of technology would like to make use of cloud technology in the future. Most of them would like to use technology for animal tracking and health, online application, GPS, yield mapping, etc.

In the present scenario, utilizing CC technology had a great scope in Ireland. The survey from farmers explained that they need more application for the herd management and financial budgeting. However, response from farmers revealed that available cloud-based application was complex to use. The Agro-Tech companies have great scope in Ireland if they develop more cloud based applications for farmers, which are mobile friendly and easy to use. The training program would be an add on to motivate the farmers.

\subsection{Farmers' View to Improve from Present System}

There were certain suggestions provided by the farmers to improve the coordination and usability of technology among farmers in Ireland. Lack of awareness among the farmers was the primary area to improve. Newspaper is the medium which is used by most of the non-adopter farmers for information seeking activities. It was observed that farmers which had very small farm areas were limited to newspaper. Discussion groups should be encouraged and should be improved because more farmers would meet and exchange information on such occasions, and utilized effectively they would bring changes in the perspective of Irish farmers towards using any technology. An expert having information on all available technologies in every discussion group of farmers is highly advantageous as suggested by one of the farmers. Selecting one farmer from the group and training him with prior knowledge with the help of government would increase the information among non-adopter farmers as well as adopted farmers on new technology. 


\section{Slow Adoption Compared to Other Countries}

According to Teagasc technological foresight 2035 report, technology adoption among Irish farmers is slow. Moreover, the same report says that educating farmers on new skills and expertise needs a fully informed advisory board, and appreciation for the change and drivers for change [3]. Demographics of age have a strong influence on the low adoption rate in Ireland. The more experienced farmers above 65 years of age strongly believe in their traditional farming and are reluctant to digitalize technology. However, when they give the farm to the next generation, they also follow the same pattern. The respondent who interviewed would like to make the use of Moocall technology even though his/her father is not ready to accept any new technology. There is a lack of a skilled and informed advisory board in Ireland to keep up to date and encourage farmers. Countries like India have small farm sizes and aged farmers like Ireland, but the advisory board having a strong interaction with farmers helps farmers to learn new technology with different schemes available to them [36]. Change in interest of the young generation is another factor that effects the adoption in Irish farms. However, the young and old generation should work in tandem to enhance the condition on farm. Moreover, most of the farms in Ireland are small; unavailability of suitable technology with less initial investment is another reason. According to the response from non-adopter and adopter farmers that the main reasons to dissuade them from using SFT is cost. There is no grant available or farmers are not aware of the grant available to use new technology. In Vietnam, companies are helping small holder farmers to adopt IoT based agriculture among farmers [37]. However, in Singapore, Agrifood and Veterinary Authority (AVA) of Singapore urge farmers to invest in emerging technology. They also have appointed dedicated people in each farm for assisting farmers in technological adoption and financial assistance [38]. Data ownership is another reason; countries like the Netherlands open the farm data for the public to help the farmers in decision making processes [39]. However, farmers in Ireland are cynical about the data sharing. The farmers' responses suggest that they want privacy of their data and that makes them not interested in programs like the Knowledge Transfer Program. However, these are the main problem that affect farmers in slow adoption compared to other countries. Unavailability of internet in remote areas persists in Irish farms and this was evident from the responses of farmers interviewed.

\section{Conclusions and Limitation}

The research helped to understand that the greater number of adoptions were among the dairy farmers. However, it is crucial to develop cloud-based applications among the beef/sheep and other farmers as well. It is positive to see that most of the young generation have positive attitude towards using cloud technology in their field. Ireland still needs attention to encourage more Agro-Tech companies to bring development in the farm with the farmers' needs. The cloud technology adoption among the young farmers was comparatively higher than among old farmers. Age, high cost, and lack of awareness are the main barriers among non-adopters while lack of allowance, unavailability, ease of use and data ownership are the barriers among adopters. This certainly supports the reason for slow adoption rate, but involvement of more young farmers will be a game changer in Irish agricultural industry and soon Irish farms in the near future will be bright. The study did not collect any details regarding farm size from the farmers who participated because research started with an objective to know the farmers' opinions towards using CC on farm but the response from farmers concluded that farm size is also one of the main barriers to adoption. However, It is difficult to project the behaviour of all Irish farmers from the sample size available, but response from farmers can be considered as the primary opinion of the Irish farmers; a whole and more detailed study is to be done for further conclusion. 
Author Contributions: J.D.V., data collection and original draft preparation; S.S. and A.K., Analyze, review, edited and supervised.

Funding: This research received no external funding.

Acknowledgments: Authors would like to acknowledge the Irish farmers for their support in this research.

Conflicts of Interest: The authors declare no conflict of interest.

\section{Appendix A. Interview Questionnaire}

The set of questions that were asked to Irish farmers during our study are as follow:

1. What are your views on maintaining the farm with help of cloud computing technology?

2. Do you think that such adoption to information technology will have a greater impact on agriculture? What's your opinion about it?

3. What will be your take if you can control the farm maintenance from one place using smart phone and computer? Do you think it will make farming easy? If no, what would be the problem?

4. Do you think the development of new information technologies on the farm would affect the role of the farmer? What's your opinion?

5. What are the factors you look for before using any information technology on your farm? What makes you wary in using any technologies?

6. What do you expect from the government or any IT companies to favor technologies on a farm?

7. As a farmer, what is your opinion regarding the strength and weakness of an Irish farmer compared to farmers from other countries?

8. Do you think there is a lack of awareness program between the farmers in Ireland in embracing any technology? If yes, how it can be improved from the present system?

9. Many countries like Israel are turning desert into agriculture with the help of smart farming technologies, what do you think the technology can change in the Irish agricultural system?

10. Do you know Knowledge Transfer Scheme? What's your opinion about that?

\section{Appendix B. Survey Questionnaire}

The set of questions that were asked to Irish farmers during our study via survey are as follow:

1. What is your Gender?

2. What is your Age group?

3. What is your education level?

4. Are you doing any job other than farming?

5. What type of farming you do?

6. Do you follow mixed farming?

7. Do you think information technology can make farm management easier?

8. Are you using any information technology in farming? (The technology such as sensors, Location-based services, automated systems, use of farm management etc can be accessed with the help of your Smartphone and computer).

9. If yes, what technology are you using?

10. What kind of record keeping do you follow to keep your farming details?

11. Are you using any cloud computing technology for your farm?

12. If yes, please specify for what purposes is it using in your farm?

13. What kind of social digital platform you use to get information about new technology in farming?

14. Currently do you use any IT application in Smartphone for any farming related services?

15. If yes, for what purpose? 
16. What is your area of preference where more farming application should be developed?

17. Would you like to adopt any information technology in future? 5a) Yes 5b) No

18. If yes, what type of technology in future?

19. What are the major difficulties in adopting technology in your farm?

20. How do you update new technology in farming?

21. If you can track all the transaction, weather, soil, crop/animal information of your farm through a platform in your mobile. Will you accept and try to learn such technology?

22. Do you follow any country that use advanced farming using information technology?

23. If yes, specify the country name?

24. What is the medium you use to communicate with other farmers in Ireland?

25. How can you rate the communication with other farmers for the exchange of information?

26. What you think about sharing information with other IT technologies can bring more development in farming?

27. If No/maybe, what would be the reason? (Please enter NIL if your previous answer to question was YES)

28. Do you like digitalizing agriculture?

\section{References}

1. Sundmaeker, H.; Verdouw, C.; Wolfert, S. Internet of food and farm 2020. In Digitising the Industry-Internet of Things Connecting Physical, Digital and Virtual Worlds; River Publishers: Delft, The Netherlands, 2016.

2. Wolfert, S.; Ge, L.; Verdouw, C.; Bogaardt, M.J. Big data in smart farming-A review. Agric. Syst. 2017, 153, 69-80. [CrossRef]

3. Teagasc|Agriculture and Food Development Authority. Teagasc Technology Foresight: Technology Transforming Irish Agri-Food and Bio-Economy; Teagasc I Agriculture and Food Development Authority: Carlow, Ireland, 2016.

4. Brewster, C.; Jan, E.; Raymond, K.F.M.; Rakers, P.; Iver, T.; Jürgen, V.; Astrid, W. Strategic Research and Innovation Agenda; ETIP Wind: Brussels, Belgium, 2018.

5. Say, S.M.; Keskin, M.; Sehri, M.; Sekerli, Y.E. Adoption of precision agriculture technologies in developed and developing countries. Online J. Sci. Technol. 2018, 8, 7-15.

6. European Agricultural Machinery. Farming 4.0: The Future of Agriculture; European Agricultural Machinery: Brussels, Belgium, 2016; pp. 1-2.

7. Department of Agriculture, Food and the Marine. Food Wise 2025 Report; Department of Agriculture, Food and the Marine: Dublin, Ireland, 2016.

8. Commission, E. Representation in Ireland. 2019. Available online: https://ec.europa.eu/ireland/tags/ representation-ireland_en (accessed on 28 March 2019).

9. European Agricultural Machinery. Digital Farming: What Does it Really Mean? European Agricultural Machinery: Brussels, Belgium, 2017.

10. Lou, W.; Ji, Z.; Sun, K.; Zhou, J. Application of remote sensing and GIS for assessing economic loss caused by frost damage to tea plantations. Precis. Agric. 2013, 14, 606-620. [CrossRef]

11. Van Es, H.; Woodard, J.; Glos, M.; Chiu, L.V.; Dutta, T.; Ristow, A. Digital Agriculture in New York State: Report and Recommendations; Cornell University: Ithaca, NY, USA, 2016.

12. Electrical Generating Systems Association (EGSA). GNSS Market Report, European Global Navigation Satellite Systems Agency; EGSA: Boca Raton, FL, USA, 2017.

13. Fulton, J. GNSS and Precision Farming; Inside GNSS: Red Bank, NJ, USA, 2015.

14. Walter, A.; Finger, R.; Huber, R.; Buchmann, N. Opinion: Smart farming is key to developing sustainable agriculture. Proc. Natl. Acad. Sci. USA 2017, 114, 6148-6150. [CrossRef] [PubMed]

15. Mazur, M.; Wisniewski, A.; McMillan, J. Clarity from above: PwC global report on the commercial applications of drone technology. Warsaw Drone Powered Solut. Pricewater House Coopers 2016, 5, 12-36. 
16. Bach, M.P.; Zoroja, J.; Loupis, M. RFID usage in European enterprises and its relation to competitiveness: Cluster analysis approach. Int. J. Eng. Bus. Manag. 2016, 8, 1847979016685093. [CrossRef]

17. Anand, N.; Vikram, P. Smart farming: IoT based smart sensors agriculture stick for live temperature and moisture monitoring using Arduino, CC and solar technology. Commun. Comput. Syst. 2016. [CrossRef]

18. Liakos, K.; Busato, P.; Moshou, D.; Pearson, S.; Bochtis, D. Machine learning in agriculture: A review. Sensors 2018, 18, 2674. [CrossRef] [PubMed]

19. Global Forum on Agriculture. How Digital Technologies Are Impacting the Way We Grow and Distribute Food; OECD Conference Centre: Paris, France, 2018.

20. World Population Prospects: The 2017 Revision, Key Findings and Advance Tables. 2017. Available online: https: / reliefweb.int/report/world/world-population-prospects-2017-revision-key-findings-andadvance (accessed on 12 January 2019).

21. Curtin, J.; Arnold, T. A Climate-Smart Pathway for Irish Agricultural Development. Exploring the Leadership Opportunity; The Institute of International and European Affairs: Dublin, Ireland, 2016.

22. Teagasc: Agriculture and Food Development Authority. An Analysis of Abatement Potential of Greenhouse Gas Emissions in Irish Agriculture 2021-2030; Teagasc: Carlow, Ireland, 2018.

23. Eleni, S.; Kostas, A.; Dimitrios, P. Review on the Trends and Challenges of Cloud Computing Technology in Climate-Smart Agriculture. In Proceedings of the 8th International Conference on Information and Communication Technologies in Agriculture, Food \& Environment (HAICTA 2017), Crete, Greece, 21-24 September 2017.

24. Ilija, S.H.; Olivera, K.; Tome, D.; Zoran, K. Farm Management Software for Increased Productivity and Competitiveness. 2017. Available online: https://www.researchgate.net/publication/320566735_Farm_ Management_Software_for_Increased_Productivity_and_Competitiveness (accessed on 22 January 2019).

25. Department of Agriculture, Food and the Marine. TAMS II Support Documents; Department of Agriculture, Food and the Marine: Dublin, Ireland, 2018.

26. Cavallo, E.; Ferrari, E.; Bollani, L.; Coccia, M. Attitudes and behaviour of adopters of technological innovations in agricultural tractors: A case study in Italian agricultural system. Agric. Syst. 2014, 130, 44-54. [CrossRef]

27. Cavallo, E.; Ferrari, E.; Bollani, L.; Coccia, M. Strategic management implications for the adoption of technological innovations in agricultural tractor: The role of scale factors and environmental attitude. Technol. Anal. Strateg. Manag. 2014, 26, 765-779. [CrossRef]

28. Cavallo, E.; Ferrari, E.; Coccia, M. Likely technological trajectories in agricultural tractors by analysing innovative attitudes of farmers. Int. J. Technol. Policy Manag. 2015, 15, 158-177. [CrossRef]

29. Lai, P. The literature review of technology adoption models and theories for the novelty technology. JISTEM-J. Inf. Syst. Technol. Manag. 2017, 14, 21-38. [CrossRef]

30. Pierpaoli, E.; Carli, G.; Pignatti, E.; Canavari, M. Drivers of precision agriculture technologies adoption: A literature review. Procedia Technol. 2013, 8, 61-69. [CrossRef]

31. Knierim, A.; Borges, F.; Kernecker, M.; Kraus, T.; Wurbs, A. What drives adoption of smart farming technologies? Evidence from a cross-country study. In Proceedings of the European International Farm Systems Association Symposium, Chania, Greece, 1-5 July 2018; pp. 1-5.

32. Keskin, M.; Sekerli, Y. Awareness and adoption of precision agriculture in the Cukurova region of Turkey. Agron. Res. 2016, 14, 1307-1320.

33. Nicol, L.A.; Nicol, C.J. Adoption of precision agriculture to reduce inputs, enhance sustainability and increase food production: A study of southern Alberta, Canada. WIT Trans. Ecol. Environ. 2018, 217, 327-336.

34. Keskin, M.; Sekerli, Y.E.; Say, S.M.; Topcueri, M. Farmers' Experiences with GNSS-Based Tractor Auto Guidance in Adana Province of Turkey. J. Agric. Fac. Gaziosmanpasa Univ. 2018, 35, 172-181. [CrossRef]

35. Hill, M. Using Farmer's Information Seeking Behaviour to Inform the Design of Extension. Ext. Farming Syst. J. 2009, 5, 121.

36. Seth, A.; Ganguly, K. Digital technologies transforming Indian agriculture. In The Global Innovation Index 2017: Innovation Feeding the World; WIPO (World Intellectual Property Organization): Geneva, Switzerland, 2017; pp. 105-111.

37. Hyea Won, L.; Vikas, C. Agriculture 2.0: How the Internet of Things Can Revolutionize the Farming Sector; Information and Communications for Development: Washington, DC, USA, 2017. 
38. Ministry of National Development. Future of Farming, AVA Vision; Ministry of National Development: Singapore, 2017.

39. Schrijver, R.; Poppe, K.; Daheim, C. Precision Agriculture and the Future of Farming in Europe: Scientific Foresight Study; European Parliament Research Service: Brussels, Belgium, 2016.

(C) 2019 by the authors. Licensee MDPI, Basel, Switzerland. This article is an open access article distributed under the terms and conditions of the Creative Commons Attribution (CC BY) license (http:// creativecommons.org/licenses/by/4.0/). 